\title{
Air-oxidation of Nb Nano-Films
}

(C) A.V. Lubenchenko ${ }^{1}$, A.A. Batrakov ${ }^{1}$, D.A. Ivanov ${ }^{1}$, O.I. Lubenchenko ${ }^{1}$, I.A. Lashkov ${ }^{1}$, A.B. Pavolotsky ${ }^{2}$, B. Schleicher ${ }^{3}$, N. Albert ${ }^{3}$, K. Nielsch ${ }^{3}$

${ }^{1}$ National Research University MPEI,

111250 Moscow, Russia

${ }^{2}$ Chalmers University of Technology,

41296 Goteborg, Sweden

${ }^{3}$ IFW Dresden, Institute for Metallic Materials,

01069 Dresden, Germany

E-mail: LubenchenkoAV@mpei.ru

$X$-ray photoelectron spectroscopy (XPS) depth chemical and phase profiling of air-oxidized niobium nanofilms has been performed. It is found that oxide layer thicknesses depend on the initial thickness of the niobium nanofilm. The increase in thickness of the initial $\mathrm{Nb}$ nano-layer is due to increase in thickness of an oxidized layer. 